\title{
Experimental study on preparation of fuel by low- temperature pyrolysis of plastic waste combined with desiccated sludge after preforming
}

\author{
Hongxin $\mathrm{Jia}^{1,2}$, Jingfu Wang ${ }^{1,2,}{ }^{*}$, and Yasong $\mathrm{Ma}^{1,2}$ \\ ${ }^{1}$ MOE Key Laboratory of Enhanced Heat Transfer and Energy Conservation, Beijing University of \\ Technology, Beijing, 100124, China \\ ${ }^{2}$ Beijing Key Laboratory of Heat Transfer and Energy Conversion, Beijing University of Technology, \\ Beijing, 100124, China
}

\begin{abstract}
Take plastic waste and dried sludge as raw materials, use pressure testing machine and high temperature hot pressing mold to test under different parameters. The effect of raw material ratio, lowtemperature pyrolysis temperature, molding pressure and heating time on the physical properties of the molded fuel after low-temperature pyrolysis, such as relaxation density, fall strength, compressive strength and water permeability, are studied. Single factor tests show that the general range of mixed molding parameters is: mixture ratio (dry sludge: composite plastics) $85: 15 \sim 75: 25$, temperature $150 \sim 250^{\circ} \mathrm{C}$, heating time $20 \sim 40 \mathrm{~min}$, compaction pressure $2 \sim 6 \mathrm{MPa}$. Orthogonal test is designed on the basis of single factor test. The results show that the most important factor affecting the relaxation density of molding fuel is molding pressure, the most important factor affecting compressive strength is the ratio of raw materials, and the most important factor affecting water permeability is heating time. The fall strength is less affected by various factors. It is due to the stickiness of the molded plastic after softening, which strengthens the "cohesion" between the raw materials, and will not be explored in the orthogonal experiment. The optimal combination of relaxation density molding parameters is the ratio (dry sludge: composite plastics) $80: 20$, temperature $250^{\circ} \mathrm{C}$, heating time $30 \mathrm{~min}$, compaction pressure $6 \mathrm{MPa}$; the optimal combination of compressive strength molding parameters is $75: 25,250^{\circ} \mathrm{C}, 30 \mathrm{~min}, 6 \mathrm{MPa}$; the optimal combination of anti-moisture absorption performance molding parameters is $85: 15,150^{\circ} \mathrm{C}, 30 \mathrm{~min}, 2 \mathrm{MPa}$.
\end{abstract}

Keywords: Dried sludge, Plastic waste, Low-temperature pyrolysis, Orthogonal test, Forming fuel.

\section{Introduction}

With the rapid economic development, my country's urban sewage treatment volume has been increasing year by year, and the sludge output has also increased [1]. It is 
estimated that my country's annual sludge output will reach 89.09 million tons in 2022 [2]. However, due to my country's long-term "heavy water over sludge", sludge treatment and disposal have not been upgraded simultaneously with sewage treatment, and the problem of sludge treatment and disposal has not been effectively solved, and the situation is very serious [3]. In addition, as a large energy consuming country, China must pay attention to energy issues [4]. According to China's national conditions, the resource utilization of sludge is of great practical significance [5].

Since sludge has low calorific value, high heavy metal content, and often has the disadvantages of pathogenic microorganisms [6], there is a greater threat to the environment [7]. How to effectively use sludge and eliminate the pollution caused by its utilization process to the environment has become the focus of people's research. The traditional disposal methods of sludge include incineration, landfill, land use, etc.[8,9], but they all have serious pollution problems. In order to reduce pollution, low-temperature pyrolysis technology as a waste utilization method has attracted widespread attention $[10,11]$, but most of the current research focuses on the use of low-temperature pyrolysis technology to prepare liquid fuels. In this paper, extrusion molding and low-temperature pyrolysis technology are combined. The dried sludge is mixed with plastic waste, then precompressed and treated by low-temperature pyrolysis technology. The obtained fuel has the advantages of high calorific value, good drop resistance, compression resistance, moisture absorption resistance, and convenient transportation and storage.

\section{Experiment materials and methods}

\subsection{Experiment materials}

The sludge used in this experiment came from the Beijing Gaobeidian Reclaimed Water Plant. The sludge was taken out and dried naturally, then crushed with a grinder, and sieved to select particles with a particle size of less than 100 meshes for use. The moulded plastics used are based on the three types of plastics that account for a high proportion of household waste: polyethylene (PE) 48\%, polypropylene (PP) 18\%, and polyvinyl chloride (PVC) 7\% [12], according to $6.5: 2.5: 1$ mixing ratio. The plastics used in the experiment are all analytically pure, and the raw material industry and element analysis of the experiment are shown in Table 1.

Table 1. Ultimate and proximate analysis of plastics.

\begin{tabular}{cccccccccc}
\hline \multirow{2}{*}{ Raw materials } & \multicolumn{4}{c}{ Ultimate analysis (\%) } & \multicolumn{5}{c}{ Proximate analysis (\%) } \\
\cline { 2 - 10 } & $\mathrm{C}_{\mathrm{ad}}$ & $\mathrm{H}_{\mathrm{ad}}$ & $\mathrm{O}^{*}$ ad & $\mathrm{N}_{\mathrm{ad}}$ & $\mathrm{S}_{\mathrm{ad}}$ & $\mathrm{M}_{\mathrm{ad}}$ & $\mathrm{A}_{\mathrm{ad}}$ & $\mathrm{V}_{\mathrm{ad}}$ & $\mathrm{Fc}_{\mathrm{ad}}$ \\
\hline Dry Sludge & 28.07 & 4.20 & 9.63 & 3.67 & 1.67 & 8.52 & 44.24 & 41.77 & 5.47 \\
Composite Plastics & 85.44 & 14.56 & 0 & 0 & 0 & 0 & 0 & 100 & 0 \\
\hline
\end{tabular}

* Means by subtraction.

\subsection{Experiment devices and methods}

\subsubsection{Experiment devices}

The test uses the RYM-600YG high temperature hot pressing mold produced by Shanghai Xinnuo Instrument Group Co., Ltd. The heating temperature range is from room 
temperature to $500^{\circ} \mathrm{C}$, and is composed of a heating mold, ordinary pressing rod, customized pressing rod, gasket, heat insulation board, and thermostat. The heating mold cavity depth is $45 \mathrm{~mm}$, and the cavity diameter is $15 \mathrm{~mm}$. There is a $5 \mathrm{~mm}$ diameter through hole in the axial center of the customized pressure rod (used to discharge the light volatiles and water vapor generated during the low-temperature pyrolysis process), and the ordinary pressure rod does not have a hole. The pressure testing machine used in the test is the microcomputer controlled constant stress pressure testing machine YAW-300B produced by Jinan Times New Technology Testing Instrument Co., Ltd. The measuring range is $0 \sim 300 \mathrm{kN}$. The pressure testing machine is mainly composed of digital control valve, pressure pump, pressure sensor and control computer.

\subsubsection{Experience methods}

In this test, the dried sludge and the molded plastic are first loaded into the mold cavity according to different ratios (100:0, 90:10, 85:15, 80:20, 75:25, 70:30). In the cavity, use a common pressure rod to pre-compress $(2,4,6 \mathrm{MPa})$ under a pressure testing machine, and maintain the maximum pressure for 30 seconds to keep the material in the mold as a cylinder with flat bottom surfaces. After the pre-compression is completed, replace the ordinary pressure rod with a customized pressure rod and raise the temperature $(100,150$, $200,250,300^{\circ} \mathrm{C}$ ), and conduct a low-temperature pyrolysis test. The pyrolysis time is set to 20, 30, 40, 50min.

\section{Experiment results and analysis}

\subsection{Single factor experiment results and analysis}

\subsubsection{Effect of mixture ratio on the physical properties of formed fuel}

This article considers that the thermal decomposition temperatures of the three plastics that make up the molding plastic are all above $200^{\circ} \mathrm{C}$. The set temperature is $200^{\circ} \mathrm{C}$, the heating time is $30 \mathrm{~min}$, the molding pressure is $4 \mathrm{MPa}$. The effects of the ratio of dried sludge and molded plastics of 100:0, 90:10, 85:15, 80:20, 75:25, 70:30 on the physical properties of the molded fuel were investigated. After the test, the performance indexes of the formed fuel were measured, and the results are shown in Figure 1.

It can be seen from the figure that when the percentage of composite plastic is $0 \sim 25 \%$, the relaxation density of formed fuel increases with the increase of composite plastic content. When the proportion of composite plastic exceeds $25 \%$, the relaxation density of formed fuel will decrease. It may be that $25 \%$ of the composite plastic is softened enough to fill the gaps of sludge particles, and the continued increase of the composite plastic will reduce the relaxation density of the formed fuel. The water permeability of formed fuel has a significant decrease with the increase of the proportion of composite plastic, mainly because the softening of composite plastic fills the gaps on the surface of formed fuel, so that water cannot penetrate into the formed fuel. The greater the proportion of composite plastic, the more obvious the filling effect. When the composite fuel is not added with plastic, the fall strength is almost zero. When the percentage of plastic is $10 \sim 30 \%$, the fall strength is greatly increased to $99.9 \%$. It is due to the softening of the plastic that acts as a binding agent, which binds the dried sludge tightly together. The compressive strength of the formed fuel increases with the increase in the percentage of the composite plastic. This is because the molded plastic becomes hard after cooling and acts as a "skeleton", which 
increases the compressive strength of the formed fuel. The increase in composite plastics also increases the number of "skeletons", so the content of composite plastics increases, and the compressive strength of formed fuels increases.

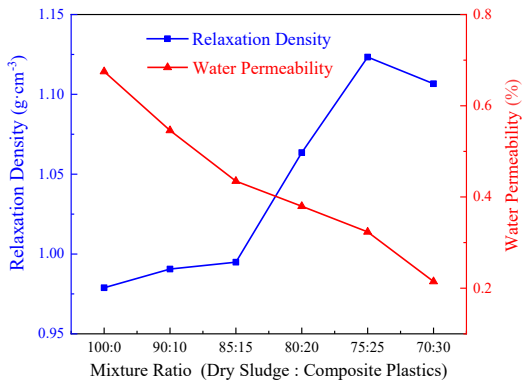

(a)

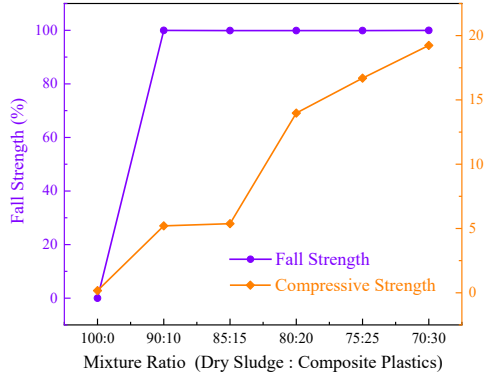

(b)

Fig. 1. Effect of mixture ratio on the physical properties of formed fuel.

\subsubsection{The influence of temperature on the physical properties of formed fuel}

Set the ratio of dry sludge to composite plastic to be $85: 15$, heating time to $30 \mathrm{~min}$, molding pressure to $4 \mathrm{MPa}$, and to investigate the effect of temperature on the physical properties of formed fuel at $100,150,200,250$, and $300^{\circ} \mathrm{C}$. After the test, the performance indexes of the formed fuel were measured, and the results are shown in Figure 2. It can be seen from the figure that the relaxation density of the formed fuel first increases and then decreases with the increase in temperature. It may be that the temperature exceeds $150^{\circ} \mathrm{C}$ and the pyrolysis of organic substances in the sludge causes the relaxation density of the formed fuel to decrease. When the temperature exceeds $200^{\circ} \mathrm{C}$, it increases again. It may be that the temperature rises, the plastic is fully softened, and the gaps left after the organic substances are precipitated are filled, and the relaxation density increases. After the temperature exceeds $250^{\circ} \mathrm{C}$, the molded plastic is separated out, causing the relaxation density of the formed fuel to drop again. The water permeation rate of molding fuels is generally declining. When heated to $100^{\circ} \mathrm{C}$, the fall strength of the formed fuel is almost zero. The temperature rises to $150^{\circ} \mathrm{C}$, the composite plastic softens and fills the gaps of the dry sludge, so the drop resistance strength is greatly increased, and then the temperature is increased, the drop resistance strength is basically unchanged. The compressive strength change trend is similar to the relaxation density, and the reasons are also similar, so I won't repeat them here. The change trend of compressive strength is similar to that of relaxation density, and the reasons are also similar. It will not be repeated here.

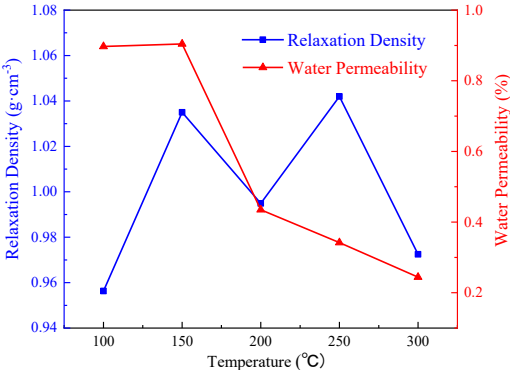

(a)

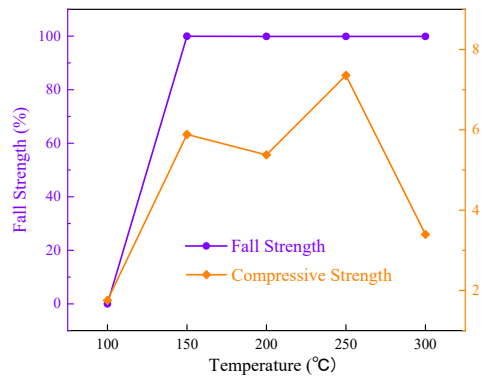

(b)

Fig. 2. The influence of temperature on the physical properties of formed fuel. 


\subsubsection{Influence of compaction pressure on physical properties of formed fuel}

The ratio of dry sludge to composite plastic was set to $85: 15$, the temperature was $200^{\circ} \mathrm{C}$, and the heating time was $30 \mathrm{~min}$. The influence of composite pressure on the physical properties of formed fuel was investigated when the composite pressure was $2 \mathrm{MPa}, 4 \mathrm{MPa}$, $6 \mathrm{MPa}$, and $8 \mathrm{MPa}$. After the test, measure the performance indexes of the formed fuel, and the results are shown in Figure 3. It can be seen from the figure that the compaction pressure is in the range of $2 \sim 8 \mathrm{MPa}$, and the formed fuel relaxation density does not change much with the compaction pressure. It may be because at $2 \mathrm{MPa}$, the composite plastic particles have been embedded in the gap of the dried sludge particles, and the continued increase of the pressure has little effect on the relaxation density. The water permeability of the formed fuel decreases with the increase of compaction pressure. It may be due to the increase of pressure that the softened plastic is better squeezed into the gap of the fuel, making it more difficult for water to penetrate into the fuel. The fall strength of the formed fuel has little relationship with the compaction pressure. The compressive strength of formed fuel increases with the increase of compaction pressure, because the increase of pressure makes the plastic particles better embed in the gap of sludge particles. After cooling, the "skeleton" becomes thicker and the compressive strength increases.

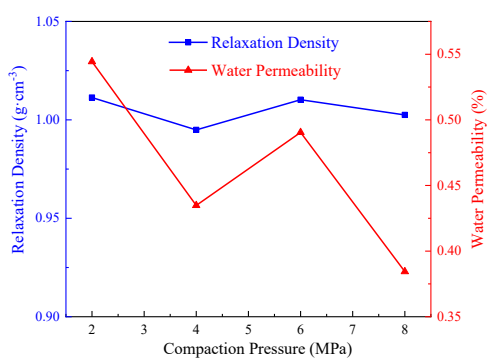

(a)

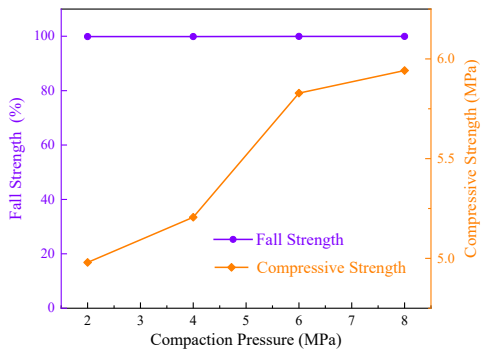

(b)

Fig. 3. Influence of compaction pressure on physical properties of formed fuel.

\subsubsection{Influence of heating time on physical properties of formed fuel}

Set the ratio of the dry sludge to the composite plastic to be $85: 15$, the temperature is $200^{\circ} \mathrm{C}$, and the compaction pressure is $4 \mathrm{MPa}$. The influence of the heating time on the physical properties of the formed fuel is investigated when the heating time is $10 \mathrm{~min}, 20 \mathrm{~min}, 30 \mathrm{~min}$, $40 \mathrm{~min}$, and 50min. After the test, the performance indexes of the formed fuel were measured, and the results are shown in Figure 4. It can be seen from the figure that as the heating time increases, the relaxation density of the formed fuel increases first, reaches a maximum at 20 minutes, and then gradually decreases, which may be due to the precipitation of organic matter in the fuel due to the extension of the heating time. The fall strength is close to $100 \%$ within the heating time of $10 \sim 50 \mathrm{~min}$, and the drop resistance effect is very good. The compressive strength of the formed fuel increases first with the extension of heating time, because the plastic softens and penetrates into the gap between the sludge particles, and acts as a "skeleton" after cooling. As time goes by, the compressive strength decreases, which may be due to the precipitation of organic matter in the sludge, which causes the gap to increase again. After 30 minutes, the compressive strength fluctuates slightly, which may be caused by a small amount of organic matter precipitation and volatilization alternately with plastic softening and filling the gap. 


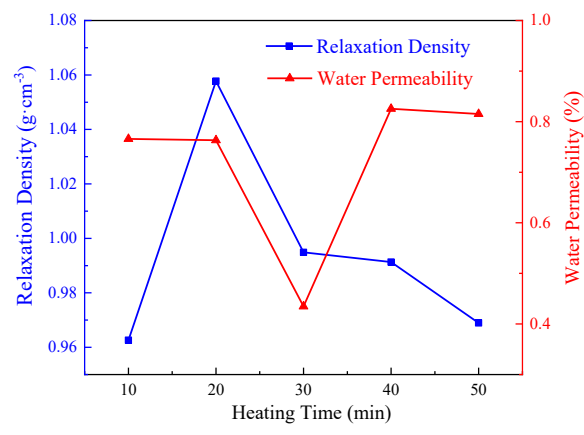

(a)

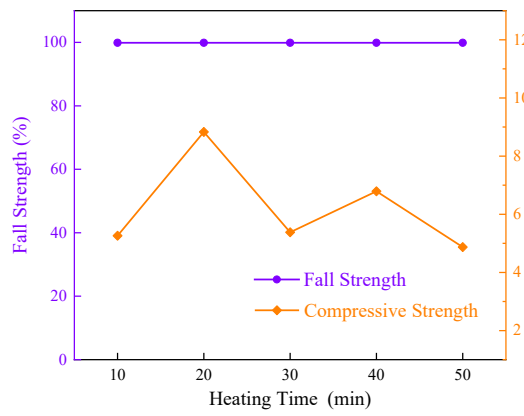

(b)

Fig. 4. Influence of heating time on physical properties of formed fuel.

\subsection{Orthogonal experiment results and analysis}

According to the single factor experiment results, determine the orthogonal experiment plan. The main factors that affect the test are: mixture ratio, temperature, heating time, compaction pressure, each factor takes 3 levels, and the $\mathrm{L}_{9}\left(3^{4}\right)$ orthogonal test table is used for the test. The orthogonal test scheme and the physical properties of the fuel after the orthogonal test are formed are shown in Tables 2 and 3. Since the fall strength of the formed fuel is better under all test factors and the change is small, the falled strength of the formed fuel is no longer tested in the orthogonal test.

Table 2. Orthogonal test scheme.

\begin{tabular}{ccccc}
\hline \multirow{2}{*}{ Number } & \multicolumn{2}{c}{ Factors } & $\mathrm{C}$ & $\mathrm{D}$ \\
\cline { 2 - 5 } & $\mathrm{A}$ & $\mathrm{B}$ & 20 & 2 \\
\hline 1 & $85: 15$ & 150 & 30 & 4 \\
2 & $85: 15$ & 200 & 40 & 6 \\
3 & $85: 15$ & 250 & 30 & 6 \\
4 & $80: 20$ & 150 & 40 & 2 \\
5 & $80: 20$ & 200 & 20 & 4 \\
6 & $80: 20$ & 250 & 40 & 4 \\
7 & $75: 25$ & 150 & 20 & 6 \\
8 & $75: 25$ & 200 & 30 & 2 \\
9 & $75: 25$ & 250 & & \\
\hline
\end{tabular}

A is the mixture ratio (dried sludge: molded plastic); $\mathrm{B}$ is the temperature $\left({ }^{\circ} \mathrm{C}\right)$; $\mathrm{C}$ is the heating time (min); D is the compaction pressure.

Table 3. Fuel physical properties after orthogonal test.

\begin{tabular}{cccccc}
\hline \multirow{2}{*}{ Physical performance metrics } & \multicolumn{4}{c}{ Factors } \\
\cline { 2 - 6 } & $\mathrm{k}_{1}$ & $\mathrm{~A}$ & $\mathrm{~B}$ & $\mathrm{C}$ & $\mathrm{D}$ \\
\hline \multirow{3}{*}{ Relaxation density } & $\mathrm{k}_{2}$ & 1.033 & 1.070 & 1.013 & 1.053 \\
& $\mathrm{k}_{3}$ & 1.080 & 1.023 & 1.130 & 1.023 \\
& $\mathrm{R}$ & 0.074 & 1.127 & 1.077 & 1.143 \\
Compressive & $\mathrm{k}_{1}$ & 5.567 & 0.104 & 0.117 & 0.120 \\
strength & $\mathrm{k}_{2}$ & 11.920 & 1.733 & 9.527 & 10.677 \\
\multirow{2}{*}{ Water permeability } & $\mathrm{k}_{3}$ & 13.357 & 13.847 & 11.393 & 9.000 \\
& $\mathrm{R}$ & 6.790 & 6.114 & 10.923 & 12.167 \\
& $\mathrm{k}_{1}$ & 0.604 & 0.701 & 0.717 & 3.167 \\
& & & & & 0.585
\end{tabular}




\begin{tabular}{lllll}
$\mathrm{k}_{2}$ & 0.407 & 0.495 & 0.329 & 0.530 \\
$\mathrm{k}_{3}$ & 0.511 & 0.326 & 0.476 & 0.407 \\
$\mathrm{R}$ & 0.197 & 0.375 & 0.388 & 0.178 \\
\hline
\end{tabular}

$\mathrm{k}_{1}, \mathrm{k}_{2}, \mathrm{k}_{3}$ represent 3 levels, and $\mathrm{R}$ represents extremely poor.

According to the range analysis in Table 3, the primary and secondary order of the factors affecting the relaxation density is $\mathrm{D}>\mathrm{C}>\mathrm{B}>\mathrm{A}$. From the mean value, $\mathrm{A}_{2}$ is the optimal level of factor $A, B_{3}$ is the optimal level of factor $B, C_{2}$ is the optimal level of factor $C$, and $\mathrm{D}_{3}$ is the optimal level of factor $\mathrm{D}$. Therefore, the optimal combination of affecting relaxation density is $\mathrm{A}_{2} \mathrm{~B}_{3} \mathrm{C}_{2} \mathrm{D}_{3}$. The primary and secondary order of the factors affecting the compressive strength is $A>B>D>C$. From the mean value, $A_{3}$ is the optimal level of factor $A, B_{3}$ is the optimal level of factor $B, C_{2}$ is the optimal level of factor $C$, and $\mathrm{D}_{3}$ is the optimal level of factor $\mathrm{D}$. Therefore, the optimal combination of affecting compressive strength is $\mathrm{A}_{3} \mathrm{~B}_{3} \mathrm{C}_{2} \mathrm{D}_{3}$. The primary and secondary order that affects the water permeability of formed fuel is $C>B>A>D$. It can be seen from the average value that $A_{1}$ is the optimal level of factor $A, B_{1}$ is the optimal level of factor $B, C_{2}$ is the optimal level of factor $C$, and $D_{1}$ is the optimal level of factor $D$. Therefore, the optimal combination that affects the water permeability of formed fuel is $\mathrm{A}_{1} \mathrm{~B}_{1} \mathrm{C}_{2} \mathrm{D}_{1}$.

\section{Conclusion}

In this paper, dry sludge and composite plastics are used to prepare formed fuels, and the physical properties of formed fuels are evaluated with relaxation density, moisture absorption resistance, fall strength, and compressive strength as indicators. The general range of the mixing molding parameters of dry sludge and composite plastic obtained through single factor experiment is: ratio (dry sludge: composite plastic) 85:15 75:25, temperature $150 \sim 250^{\circ} \mathrm{C}$, time $20 \sim 40 \mathrm{~min}$, The compaction pressure is $2 \sim 6 \mathrm{MPa}$.

For each physical performance measurement index, the degree of influence of different molding parameters is different. This paper designs orthogonal experiments to analyze the degree of influence of different molding parameters on the physical properties of formed fuel and analyzes the optimal combination of molding parameters. The most important factor affecting the relaxation density of formed fuel is compaction pressure. The most important factor affecting compressive strength is the ratio of raw materials. The most important factor affecting water permeability is heating time. The fall strength is less affected by various factors. It is due to the adhesiveness of the composite plastic after softening, which strengthens the "cohesion" between the raw materials. It will not be explored in the orthogonal experiment. The optimal combination of relaxation density molding parameters is the ratio (dry sludge: composite plastic) $80: 20$, temperature $250^{\circ} \mathrm{C}$, time $30 \mathrm{~min}$, compaction pressure $6 \mathrm{MPa}$; The optimal combination of compressive strength molding parameters is $75: 25,250{ }^{\circ} \mathrm{C}, 30 \mathrm{~min}, 6 \mathrm{MPa}$; The optimal combination of antihygroscopicity molding parameters is $85: 15,150^{\circ} \mathrm{C}, 30 \mathrm{~min}, 2 \mathrm{MPa}$.

In the experiment, it is found that adding plastic not only helps to increase the calorific value of the fuel, but also acts as a "binder" after the plastic is softened, which greatly improves the physical properties of the fuel.

\section{References}

1. Y. Xiao, et al., Pretreatment, modification and applications of sewage sludge-derived biochar for resource recovery- A review. Chemosphere, 2021. 287: p. 131969.

2. Y. Y. Wang, et al., Pyrolysis of municipal sludge and utilization of its soild residues. Industrial Minerals and Processing, 2020. 49(12): 41-45. 
3. X. H. Dai, Present situation and development trend of sludge treatment and disposal in China. National Conditions, 2020. 72(6): 30-34.

4. T. Z. Zhang, Discussion on the Current Situation and Development Trend of Energy Utilization in China. Territory and Natural Resources Study, 2021. 5: 76-78.

5. J. Wang, et al., Review of sludge energy utilization technology. Modern Chemical Industry, 2021. 1-4.

6. L. S. Luo, Research progress of sludge disposal technology in urban sewage treatment projects in China. Technology And Market, 2020. 27(12): 93-94.

7. Raj, A., et al., Preparation, characterization and agri applications of biochar produced by pyrolysis of sewage sludge at different temperatures. Science of The Total Environment, 2021. 795: p. 148722.

8. J. Zhou, Analysis on the Ways to Utilize the Sludge in Municipal Wastewater Treatment Plants. China Resources Comprehensive Utilization, 2021. 39(6): 80-82.

9. Chen, R., et al., Upgrading of sewage sludge by low temperature pyrolysis: Biochar fuel properties and combustion behavior. Fuel, 2021. 300: p. 121007.

10. Q. Wang, et al., Emission characteristics of shoreline plastics during low-temperature pyrolysis process. China Environmental Science, 2021. 41(08): 3684-3692.

11. S.R. Naqvi, R. Tariq, M. Shahbaz et al. Recent developments on sewage sludge pyrolysis and its kinetics: Resources recovery, thermogravimetric platforms, and innovative prospects. Computers and Chemical Engineering, 2021. 150: p. 107325.

12. Y. B. Liu, et al., Copyrolysis Characteristics and Kinetic Analysis of Typical Constituents of Plastic Wastes. Proceedings of the CSEE, 2010. 30(23): 56-61. 